\title{
Mobile right ventricular myxoma traversing chambers during cardiac cycle
}

\author{
Adam Khan, BA, ${ }^{a}$ Nicholas R. Teman, $\mathrm{MD},{ }^{\mathrm{b}}$ and Bo Yang, $\mathrm{MD}, \mathrm{PhD}^{\mathrm{c}}$
}

A 19-year-old man was evaluated for chest pain on exertion. The patient demonstrated a grade III systolic murmur with a loud systolic "plop," heard best at the left upper sternal border, accompanied by a palpable precordial lift. A transthoracic echocardiogram demonstrated a $5.8-\mathrm{cm} \times 3.3-\mathrm{cm}$ multilobuted mass in the dilated right ventricle. During diastole, the mass sat near the free wall of the right ventricle (Figure 1, A). On systole, the mass demonstrated prolapse into the dilated right atrium, with associated mild tricuspid regurgitation (Figure 1, B). Cardiac magnetic resonance imaging with gadolinium again demonstrated a mobile mass travelling between the chambers during the cardiac cycle (Figure 2).

The patient underwent uncomplicated resection of the right ventricular tumor with the base deeply embedded within the trabeculae carneae. The tumor was visualized in the right atrium and was connected to a $0.5-\mathrm{cm}$ thick stalk emanating from approximately $1.5 \mathrm{~cm}$ below the tricuspid annulus at the anterior free wall of the right ventricle (Figure 3). The pathology report confirmed a tumor consistent with myxoma. At the follow-up examination, 1 year after the operation, the patient was asymptomatic, with no reported chest pain or systolic murmur.

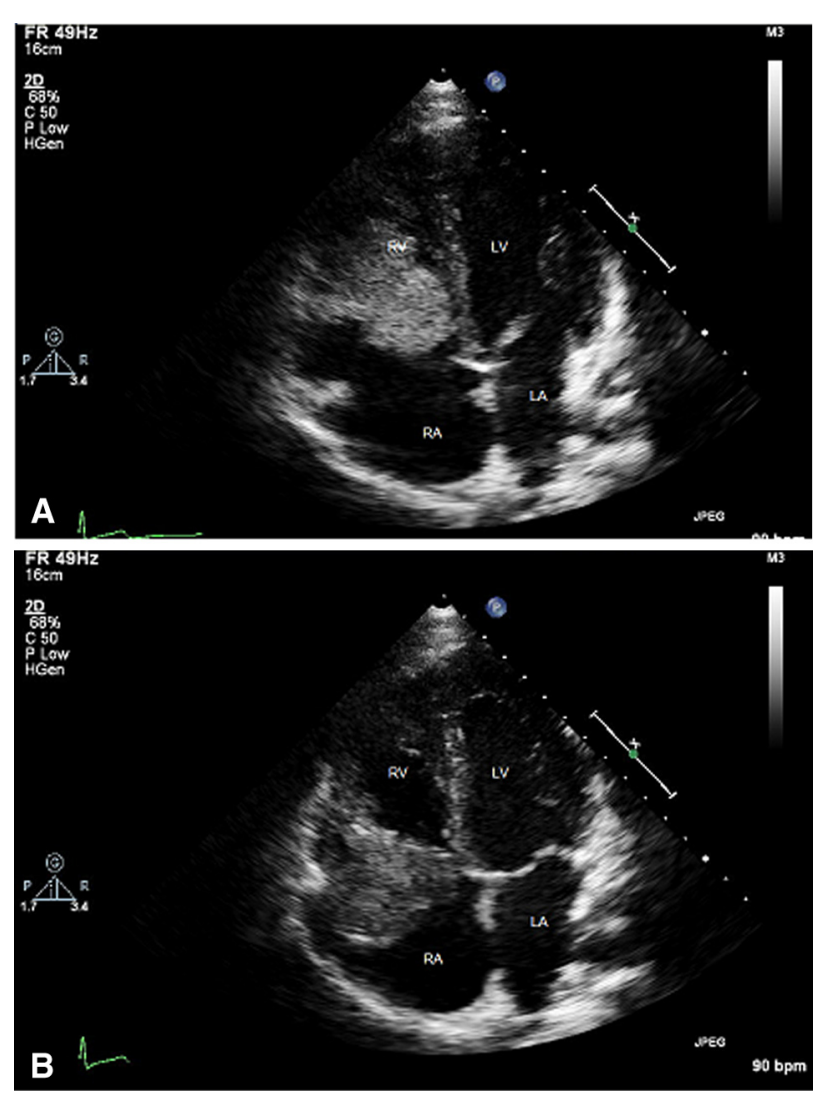

FIGURE 1. Transthoracic echocardiogram. A, During diastole, the mass was located next to the free wall of the right ventricle $(R V)$. B, During systole, the mass appeared in the right atrium $(R A) . L V$, Left ventricle; $L A$, left atrium.

From the Department of Surgery, ${ }^{\mathrm{b}}$ University of Michigan Medical School, ${ }^{\mathrm{a}}$ Ann Arbor, Mich; and Department of Cardiac Surgery, ${ }^{c}$ University of Michigan Cardiovascular Center, Ann Arbor, Mich.

Disclosures: Authors have nothing to disclose with regard to commercial support.

Received for publication Feb 28, 2014; accepted for publication March 12, 2014; available ahead of print April 19, 2014.

Address for reprints: Adam Khan, BA, University of Michigan Medical School, 1301 Catherine Rd, Ann Arbor, MI 48104 (E-mail: aalamgir@umich.edu).

J Thorac Cardiovasc Surg 2014;148:3240-1

0022-5223/\$36.00

Copyright (c) 2014 by The American Association for Thoracic Surgery

http://dx.doi.org/10.1016/j.jtcvs.2014.03.025 


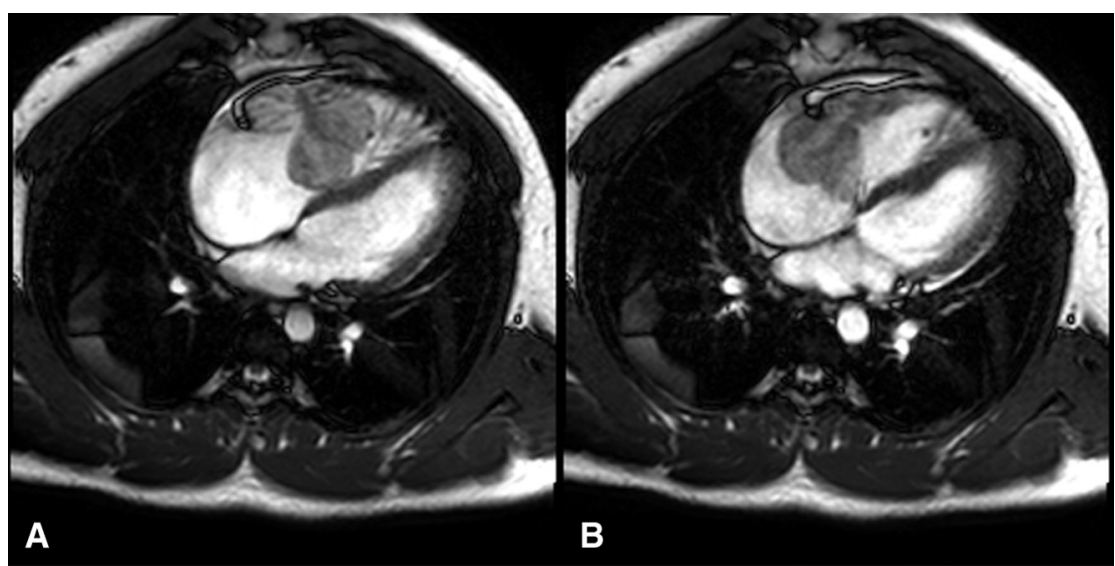

FIGURE 2. Magnetic resonance imaging scan. A, During diastole, the mass could be seen with a visible stalk tethered to the trabeculae of the right ventricular wall. B, During systole, the mass was displaced into the right atrium.
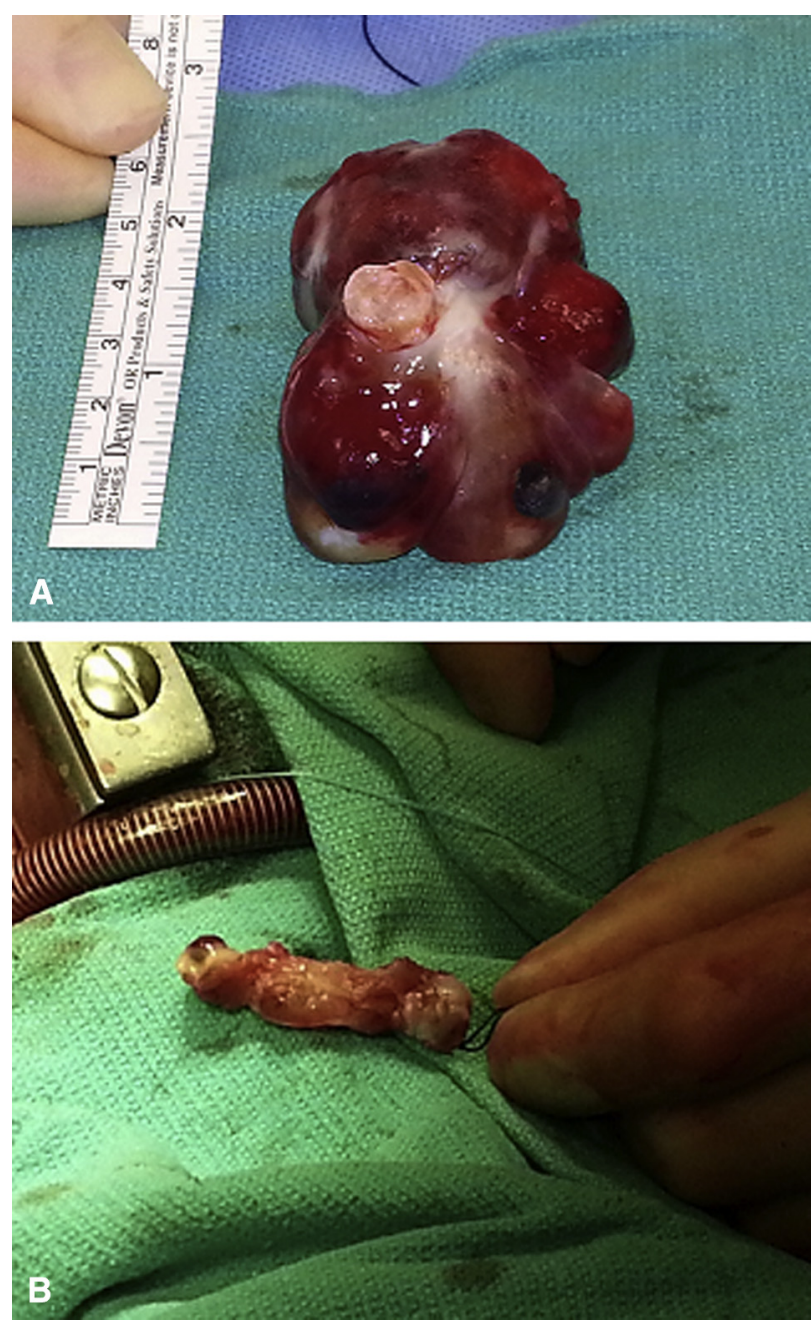

FIGURE 3. Photographs of resected specimens. A, Initially resected main portion of the myxoma measuring $5.5 \times 4.5 \times 3.0 \mathrm{~cm}$. B. The second portion of the myxoma, measuring $4.0 \times 1.0 \times 0.9 \mathrm{~cm}$, with the stalk found embedded in the trabeculae carneae. 